\section{Sticky fingers}

Glucose reagent strips are widely used in accident and emergency (A\&E) departments to facilitate the early detection of abnormal blood glucose levels or the presence of glucose in the urine. Early accurate evaluation of glycaemic status is an essential part of the initial management of a collapsed or confused patient.

Used correctly, these reagent strips provide blood glucose estimations that correlate well with hospital laboratory results. ${ }^{1}$ Their accuracy is further enhanced by the use of reflectance meters. ${ }^{2}$ Documented sources of error include poor user technique, inadequate sample size, inaccurate timing or the use of outdated or incorrectly stored strips. ${ }^{2-4}$

We wish to report two cases illustrating another important source of error in the use of glucose reagent strips which resulted in unnecessary investigation and a potentially serious delay in treatment.

\section{Case one}

A 32-year-old female, known to be an insulin dependant diabetic, presented to the A\&E department with a clinical picture of hypoglycaemic coma. Initial finger prick testing of capillary blood (BM-Test 1-44 reagent strip, Boehringer Mannheim and Reflolux $S$ reflectance meter, Boehringer Mannheim) indicated a blood glucose concentration of greater than 44

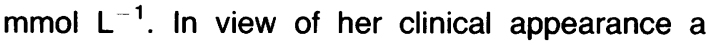
venous sample of blood taken for laboratory estimation of glucose concentration was also tested with a fresh reagent strip. This showed a blood glucose concentration of less than $2 \mathrm{mmol} \mathrm{L}^{-1}$. An intravenous bolus of $50 \mathrm{~mL}$ of $50 \%$ glucose solution was immediately administered with prompt improvement in her clinical condition. A more detailed history revealed that her husband, on recognizing the signs of impending hypoglycaemia had tried to spoon feed her with sugar. As her conscious level deteriorated she was seen to lick and suck her fingers before lapsing into coma. The spurious initial high reading was caused by contamination of her fingers with saliva and sugar solution.

\section{Case two}

A 24-year-old male was admitted to the observation ward with a minor head injury. Routine ward testing of his urine revealed glycosuria. (BM-Test- $5 \mathrm{~L}$ reagent strip, Boehringer Mannheim). A repeat sample the same day showed no evidence of glycosuria and a fasting blood sugar estimation was normal. On further questioning the patient admitted that he provided the first sample of urine immediately after eating a marmalade sandwich. Subsequent investigations revealed that he had contaminated the neck of the sample jar with marmalade from his fingers.

Glucose reagent strips have an important role in the initial evaluation of the confused or unconscious patient. These two cases identify contamination of the skin with exogenous sugar solution as another potential source of error. We wish to reiterate the importance of careful skin cleaning prior to obtaining a capillary sample of blood and the need to interpret with caution any investigation that clearly conflicts with the clinical condition of the patient.

\section{REFERENCES}

1. Cheeley R.D. \& Joyce S.M. (1990) A clinical comparison of four blood glucose reagent strips. American Journal of Emergency Medicine 8(1), 11-15.

2. Anonymous (1993) Meters for measuring blood glucose at home. Drug and Therapeutics Bulletin 31(8), 30-32.

3. Anonymous (1987) Consensus statement on selfmonitoring of blood glucose. Diabetes Care 10, 95-99.

4. Colagiuri R., Colagiuri S., Jones S. \& Moses R.G. (1990) The quality of self-monitoring of blood glucose. Diabetic Medicine 7(9), 800-804.

\section{WATTS \& J. STEVENSON, FRCS Accident and Emergency Department, Sunderland District General Hospital, Sunderland}

\section{Non-traumatic acute haemoperitoneum due to hepatocellular carcinoma: short report}

On a world-wide basis, hepatocellular carcinoma is the most prevalent neoplasm today. We report a case of acute haemoperitoneum, due to hepatocellular carcinoma in a non-endemic area. Such a presentation is, however, relatively common in young males in endemic areas.

A 25-year-old adult male presented to the surgical casualty wing of the hospital, with features suggestive of acute non-traumatic haemoperitoneum. The only relevant point in the history being a vague right upper quadrant discomfort noted 2 weeks previously. At emergency laparotomy bleeding was noted from the tumour surface on the under surface of the right 
lobe of the liver. A solitary satellite nodule was present. Biopsy confirmed hepatocellular carcinoma. Right hemihepatectomy was performed.

Five year survival rates following resection range from $11-46 \%$, with the current operative mortality being stated to be around $5 \%$. To reduce the incidence of post-operative liver failure in patients with accompaying cirrhosis, wedge resection should be the procedure of choice.

R.P. KUMAR

Postgraduate in Surgery

Palkulangara, Trivandrum,

Kerala State, South India 